\title{
Trazabilidad una característica para un artículo científico
}

\section{Traceability, one characteristic for a scientific paper}

\section{Leonardo Romero}

Instituto de Investigaciones de Ciencias Biológicas Antonio Raimondi, Facultad de Ciencias Biológicas, Universidad Nacional Mayor de San Marcos. Apartado 110058, Lima 11, Perú.

Email: Iromeroc@unmsm.edu.pe

Cuando nos referimos a la personalidad de una revista, en realidad pensamos en la trayectoria que la revista toma durante un tiempo determinado. Esa trayectoria esta dada por la temática, la orientación y los criterios de calidad para aceptar o rechazar los artículos. Pero además cada revista se enfrenta a particulares condiciones. En el caso de la Revista Peruana de Biología podemos mencionar que su temática principal, la biodiversidad, es un concepto de implicancias no solamente del ámbito de la ciencia-biología sino que involucra directamente a la sociedad, la economía y las decisiones políticas. En las siguientes líneas presentaré la necesidad de mejorar la información de nuestros trabajos y de mantener vínculos entre nuestros artículos, colecciones científicas, bases de datos y sociedad.

\section{Querer opinar}

Las revistas científicas nacieron en el seno de las reuniones organizadas por sus comunidades y han venido siendo el sistema de comunicación, registro y archivo de descubrimientos, observaciones, investigaciones y teorías. Dentro de una revista científica, podríamos concebir cada artículo como alguien que pide la palabra en una larga e interminable lista, para opinar sobre un importante y trascendental tema para la institución (la ciencia) y la sociedad.

La revista científica adquiere su personalidad principalmente por la interacción entre los autores, editores y revisores, los tres integrantes de la comunidad científica que sustenta a la revista. En Latinoamérica y en partícular en el Perú, una revista científica no puede ser vista como un simple repositorio de artículos, escritos por intereses dispares, influenciados por circunstancias personales o del mainstream internacional, sino que se ve involucrada con otros roles más, por ejemplo el de cohesionar y fortalecer la comunidad científica, de proyectarse sobre la sociedad, el país y la región, y también de generar una visión y una propuesta a los temas y problemas que trate.

\section{La biodiversidad y la responsabilidad}

Aunque la Revista Peruana de Biología podría acoger una amplia gama de investigaciones del área de la biología, ella ha mostrado siempre como principal tendencia la divulgación de las investigaciones en biodiversidad.

Hace algún tiempo un colega me comentaba el siguiente paralelo:

"Dar a conocer la posición geográfica de una rara y bella orquídea puede causar la extinción de la misma. Sin embargo dar a conocer la posición geográfica de otra planta que produce un alcaloide y que es conocida por las tribus del lugar por su valor curativo, permitiría posteriormente solicitar una compensación económica por su explotación”.

De hecho los investigadores que trabajan con la biodiversidad tienen una gran responsabilidad en sus manos y deben siempre estar concientes que detrás de su labor hay múltiples intereses. En las investigaciones en biodiversidad el científico no se ubica solamente en el discurso científico, sino en el ámbito técnico, social, político y económico.

\section{Investigaciones, biodiversidad y la divulgación del conocimiento.}

Con la aceptación del concepto de biodiversidad, nos vemos obligados a abandonar la precaria idea que la naturaleza (la biodiversidad) era de nadie o de todos. En el concepto de biodiversidad todos los sistemas (entre ellos la sociedad), son interrelacionados. En la actualidad distintas áreas del conocimiento han convergido desde diferentes ópticas en el estudio de la realidad donde el hombre es una parte consustancial. Investigar el material genético, la biodiversidad genética, implica tener muy presentes los alcances sociales y económicos de la biodiversidad. Entonces los editores de revistas científicas al igual que nos guiamos por principios éticos y leyes para evitar malos comportamientos con respecto a la investigación con humanos y animales, también debemos incorporar normas para los trabajos con biodiversidad.

"Las bioprospecciones son el talón de Aquiles del desarrollo biotecnológico. Es entonces necesario que los científicos asuman su parte de responsabilidad, la naturaleza, no puede ser expropiada, aunque sean organismos que no hayan interaccionado con el hombre, organismos marítimos, zonas vírgenes, aguas termales, etc. Es por esto que se convierte en imprescindible que los científicos contribuyan a la elucidación de caminos que den respuesta a estos conflictos, uno de ellos podría ser la trazabilidad a origen de las muestras biológicas. Si se conoce la procedencia de un gen, de una cDNA, geográficamente, de la especie, se podrá afrontar mejor el reparto de beneficios" ${ }^{1}$.

\section{La trazabilidad}

Debemos entender que no solamente los investigadores que realizan trabajos sobre taxonomía, etnobiología o ecología deben pormenorizar sus observaciones, sino en general todos los que trabajan con la biodiversidad.

Las publicaciones de ensayos sobre características bioquímicas, propiedades farmacológicas o industriales ya sean de plantas o animales, son parte del interés de conocer, registrar o validar los usos de la biodiversidad. Los artículos que versan sobre estos temas tienen diferentes niveles de análisis, por lo menos en la Revista Peruana de Biología, y van desde análisis proximales y screening hasta elaborados bioensayos. En cada caso la exactitud 
en la descripción de los procedimientos, nos indica la calidad de la información. Sin embargo es frecuente el desden sobre el hacer referencia a alguna forma de vinculación entre los materiales como lo son: la información de especie, características de individuos y procedencia geográfica, con los resultados. Esta falta puede deberse a varios factores, pero el más conspicuo es aquel relacionado al gran esfuerzo que se hace sobre el aspecto técnico, la obtención de un resultado cuantitativo en abstracto sin prever o tomar conciencia de la trascendencia en la generación de esa información.

El concepto de trazabilidad o rastreabilidad lo define La Organización Internacional de Normalización (ISO 8402:1994) como la "capacidad para rastrear los antecedentes, la aplicación o la ubicación de una entidad por medio de identificaciones registradas." Encontramos su uso en el ámbito de los conceptos de calidad de procesos industriales o productivos. También podemos referirnos a la trazabilidad ${ }^{2}$ como la capacidad para reconstruir la historia, recorrido o aplicación de un determinado producto, identificando:

- Origen de sus componentes.

- Historia de los procesos aplicados al producto.

- Distribución y localización después de su entrega.
Aplicando este concepto al ámbito de los artículos científicos que estudian a la biodiversidad nos obligaría a incluir en la descripción de los materiales los vínculos necesarios para asegurar, no solo la posibilidad de repetir los resultados, sino para enfrentar las posibles consecuencias que de los resultados o del uso de los resultados se desprendan, como por ejemplo el reconocimiento del etnoconocimiento en los procesos de patentamiento de productos de origen biologico ${ }^{3}$.

${ }^{1}$ Bota, A. 2003. Contribución de las normas CIOMS 2002 al desarrollo biotecnológico. La corresponsabilización del científico. Biol. Res. 36(2): 148-154

${ }^{2}$ Wikipedia, la enciclopedia libre. 2007. Trazabilidad. <http:// es.wikipedia.org/wiki/Trazabilidad> acceso:17/08/07

${ }^{3}$ Herrera S. \& E. Rodríguez. 2004. Etnoconocimiento en latinoamérica. Apropiación de recursos genéticos y Bioética. Acta Bioética. X(2): 181-190 